Disponível em

http://www.anpad.org.br/rac

RAC, Rio de Janeiro, v. 18, Edição Especial, art. 5, pp. 86-108, Dezembro 2014

http://dx.doi.org/10.1590/1982-7849rac20141876

$($ (c) EY-No

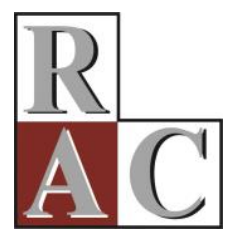

\title{
Competição Bancária: Comparação dos Comportamentos de Bancos Públicos e Privados
}

\author{
Banking Competition: Comparison of Public and Private Bank Behavior
}

Tiago Sammarco Martins

E-mail: tiagosammarcomartins@gmail.com Insper Instituto de Ensino e Pesquisa; Banco Votorantim - BV Financeira Rua Quatá 300, 04546-042, São Paulo, SP, Brasil.

Adriana Bruscato Bortoluzzo

E-mail: adrianab@insper.edu.br

Insper Instituto de Ensino e Pesquisa Rua Quatá 300, 04546-042, São Paulo, SP, Brasil.

Sérgio Giovanetti Lazzarini E-mail: sergiogl1@insper.edu.br Insper Instituto de Ensino e Pesquisa Rua Quatá 300, 04546-042, São Paulo, SP, Brasil. 


\title{
Resumo
}

Os bancos públicos representam uma parcela importante do mercado bancário no Brasil e no mundo, e têm sido utilizados como instrumentos dos governos para buscar objetivos sociais e políticos. Apesar de um dos principais argumentos para a existência de bancos públicos ser o incentivo à competição, esse papel ainda é controverso na literatura. Este artigo analisa o mercado bancário brasileiro no período de 2000 a 2011, calculando o nível de competição entre bancos públicos e privados, e suas reações às medidas adotadas pelo governo brasileiro durante a crise mundial de 2008, período em que este adotou publicamente a postura de exercer pressão política sobre os bancos públicos para aumento de concessões de crédito e redução de taxas de juros. Com base nos resultados de um modelo de regressão em três estágios, visando estimar o índice de Lerner dos bancos, foi constatado que os bancos públicos apresentam comportamento mais próximo à competição perfeita do que os privados, ainda que aqueles tenham algum poder de mercado. Também foi observada mudança de comportamento dos bancos após a crise de 2008, tanto para os públicos como para os privados, sendo que ambos apresentaram aumento em seus níveis de competição.

Palavras-chave: bancos públicos; bancos privados; crédito; competição; índice de Lerner.

\begin{abstract}
Public banks are an important part of the banking market in Brazil and abroad, and they have been used to implement strategies furthering political and social goals. Although one of the main arguments for the existence of public banks is to encourage competition, this role remains controversial in literature. This paper analyzes the Brazilian banking market during the period from 2000 to 2011, calculating the level of competition between private and public banks, and their reactions to the measures adopted by the Brazilian government during the world crisis of 2008, when the government adopted a policy of publicly influencing public banks to increase loan approvals and reduce interest rates. From results obtained through three stage least squares estimation of the Lerner index, we found that public banks exhibit behavior closer to perfect competition than private banks, even though they can exert some market power. We also observed a change in competitive behavior after the 2008 crisis for both public and private banks, which displayed an increased in pro-competitive behavior.
\end{abstract}

Key words: public banks; private banks; credit; competition; Lerner index. 


\section{Introdução}

A importância dos bancos públicos pode ser caracterizada tanto pela sua representatividade quanto por sua influência no mercado bancário. Mesmo com a onda mundial de privatizações nos anos 90, os bancos públicos representavam aproximadamente $40 \%$ do total de ativos do setor bancário mundial em 1995 (La Porta, Lopez-de-Silanes, \& Shleifer, 2002). Esta parcela é destacada em países em desenvolvimento, inclusive nos industrializados, com valores superiores a $45 \%$ e $20 \%$, respectivamente (Levy-Yeyati, Micco, \& Panizza, 2004).

Quanto à influência no mercado bancário, os bancos públicos apresentam comportamentos potencialmente diferenciados dos demais devido às suas características distintas. Esses bancos têm, em geral, objetivos que não estão ligados somente à maximização de lucro (Levy-Yeyati et al., 2004; Musacchio \& Lazzarini, 2014). Diversos autores ressaltam que os empréstimos dos bancos públicos são sensíveis a ciclos políticos, isto é, tais bancos parecem estar sujeitos à influência do governo em exercício (Dinç, 2005; Sapienza, 2002). Ainda, bancos públicos também podem atuar em mercados distintos ou de pouco interesse por bancos privados (por exemplo, crédito agrícola ou de muito longo prazo).

Nesse artigo, será discutida uma motivação adicional para a existência de bancos públicos: atuar como instrumento de controle da competição por parte dos governos. Atuando como participante do mercado com uma função objetivo diferente da maximização de lucros, esses bancos podem causar reações competitivas que garantam menores preços, visando a atender objetivos sociais do governo (Banco Interamericano de Desenvolvimento, 2005) ou simplesmente aumentar sua popularidade junto aos eleitores. Por exemplo, no Brasil, após a crise financeira mundial de 2008, o governo federal adotou a ação de publicamente influenciar os bancos públicos para concessão de crédito e redução de taxa de juros, enquanto todo o mercado caminhava na direção contrária (ver, por exemplo, Faria, 2009; Sciarretta, 2008).

Contudo, contrariamente a essa visão dos bancos públicos como influenciadores da competição, diversos estudos empíricos encontraram que eles não parecem afetar de forma intensa o grau de competição setorial (Bichsel, 2006; Coelho, Mello, \& Resende, 2013; La Porta et al., 2002; Sapienza, 2002). Assim, é de grande interesse a realização de novas análises que possam contribuir para o entendimento da dinâmica competitiva dos bancos públicos e privados. É esperado que tais análises contribuam na prática da gestão estratégica dessas instituições, dos órgãos reguladores e dos governos controladores dos bancos públicos.

Este trabalho, em particular, busca trazer novas evidências empíricas para contribuir no entendimento do comportamento competitivo de bancos públicos e privados, com base em dados do contexto brasileiro. Mais especificamente, o objetivo desta pesquisa é analisar a diferença no comportamento competitivo destes bancos por um período extenso de tempo, e verificar como esse comportamento muda após um evento de crise - no caso, a crise financeira de 2008, que causou uma forte redução na oferta de crédito (Freitas, 2009) e levou a uma ação governamental para influenciar os bancos públicos, visando atenuar esse cenário de crédito mais escasso. Para tanto, este trabalho analisa o mercado bancário brasileiro de 2000 até 2011, beneficiando-se desse evento como uma forma de avaliar a resposta dos bancos públicos e privados.

Por meio de metodologia quantitativa proposta por Bresnahan (1982) e utilizada nos trabalhos de Angelini e Cetorelli (2003), Uchida e Tsutsui (2005) e Kubo (2006), buscou-se analisar diferenças de atuação competitiva de bancos públicos e privados a partir de estimativas da sua margem de lucro segundo o índice de Lerner. Quanto menor o índice, mais próximo da competição perfeita atua a empresa. Dessa forma, é possível estimar não somente a intensidade de competição das empresas, como também se ela variou ao longo do tempo. 


\section{Revisão de Literatura e Hipóteses}

\section{Motivações para a existência dos bancos públicos}

Há grande controvérsia se as intervenções do Estado no mercado financeiro realmente contribuem para o bem estar social. Neste trabalho, é analisada especificamente a forma de atuação do governo por meio dos bancos públicos. O objetivo é verificar se a existência e a forma de atuação dos bancos públicos podem afetar padrões de competição no setor bancário.

De uma forma geral, a atuação do Estado na economia é justificada em várias frentes. Defensores de política industrial argumentam que bancos públicos podem reduzir problemas de escassez de crédito e ajudar no financiamento de projetos complexos de longo prazo (Amsden, 2001; Gerschenkron, 1962). Esse é o caso dos chamados bancos de desenvolvimento, financiados e controlados pelo governo (Musacchio \& Lazzarini, 2014). Porém, o foco desse estudo são bancos comerciais que afetam linhas de crédito de uma forma mais ampla. Nesse sentido, proponentes da chamada visão social de empresas estatais colocam que essas empresas buscam objetivos além de puro lucro (Ahroni, 1986; Shapiro \& Willig, 1990). Por exemplo, governos podem criar bancos públicos para atender áreas mais remotas ou segmentos de consumidores mais arriscados (Matthey, 2010; Vasconcelos, Fucidji, Scorzafave, \& Assis, 2004). Há também o argumento - enfatizado no presente estudo - de que bancos públicos podem aumentar a competição setorial (Pinheiro, 2007 como citado em Pinheiro \& Oliveira, 2007). Além de influenciarem o comportamento das instituições privadas, os bancos estatais poderiam, segundo o argumento, entrar em áreas ou segmentos de menor interesse pelo setor privado. Há, entretanto, correntes na literatura enfatizando que empresas estatais tendem a ser menos eficientes que as privadas (para uma revisão, ver Megginson, 2005). A menor eficiência da gestão pública não é exclusividade de bancos, pois a administração pública em geral é bastante criticada por problemas de incentivos. Bartel e Harrison (2005), por exemplo, deixam claro que a menor eficiência de empresas públicas pode ocorrer por dois motivos: (a) problemas de agência, relacionados ao baixo nível de monitoramento associado ao controle do governo; e (b) ambiente a que essas empresas estão expostas, geralmente com monopólio estatal e orçamentos menos rígidos dada a possibilidade de serem salvas caso se encontrem em insolvência.

É importante citar, ainda, o problema de influência política nessas empresas. Sapienza (2002), analisando dados microeconômicos do mercado de crédito na Itália, observou que a visão predominante na atuação dos bancos públicos não era objetivando a maximização do bem estar social nem era explicada pela visão de agência, mas sim pela atuação política: os bancos públicos eram utilizados como ferramenta política para distribuição de favores. Isso pode ser ilustrado pela descoberta de esquemas de corrupção e fraude envolvendo partidos políticos e bancos estatais italianos em 1993. Na mesma linha, Dinç (2005) encontra que, em anos de eleição em mercados emergentes, a atividade de empréstimo de bancos estatais é maior que a de bancos privados.

O uso político dos bancos públicos também foi identificado por La Porta, Lopez-de-Silanes e Shleifer (2002). Esses autores trazem resultados mostrando que o controle do governo politiza o processo de alocação de recursos e reduz a eficiência dos bancos públicos. Foram analisados diretamente os impactos de bancos públicos no desenvolvimento dos países, e concluiu-se que estes não contribuem para o desenvolvimento do sistema financeiro, pois grande parte dos bancos públicos está em países pobres, com baixo desenvolvimento financeiro e institucional.

Em seu estudo empírico, Levy-Yeyati, Micco e Panizza (2004), por um lado encontram evidências que apoiam a visão de que os bancos públicos não alocam o crédito de forma ótima e acabam inibindo o desenvolvimento financeiro; por outro, nenhuma evidência é encontrada para apoiar a ideia de que os bancos públicos podem acelerar o crescimento ou reduzir a volatilidade econômica do país. 


\section{Bancos públicos incentivam a competição?}

Apesar das críticas relativas à existência e à necessidade de bancos públicos, existem evidências de que tais bancos podem exercer função anticíclica em momentos de contração econômica (Micco \& Panizza, 2006). Essa atuação é oposta ao comportamento dos bancos privados, que é predominantemente pró-cíclico: em momentos de crescimento econômico, expandem a oferta de crédito, e a reduzem em períodos recessivos; dessa forma, potencializam tanto os períodos de crescimento quanto eventuais crises (Oliveira, 2006).

Segundo o Banco Interamericano de Desenvolvimento (2005), os bancos públicos podem, de fato, contribuir para a competição no mercado financeiro, especialmente quando as agências de defesa e os reguladores do sistema financeiro forem fracos. Apesar disso, ainda não foram encontrados estudos acadêmicos comprovando que estes bancos aumentaram a competição bancária.

O comportamento mais competitivo dos bancos públicos não pode ser atribuído simplesmente por preços mais baixos, pois devem se considerar outros efeitos na composição do poder de mercado. Apesar dos bancos públicos tenderem a possuir menor eficiência operacional, eles estão expostos a oportunidades de captação mais baratas que os bancos privados (Matthey, 2010). Assim, deve ser analisado o comportamento competitivo, considerando os custos individuais de cada instituição.

Existem poucos estudos empíricos analisando se os bancos públicos conseguem cumprir esse papel de incentivo à competição, e suas conclusões são negativas. Bichsel (2006) observa que os bancos cantonais suíços, apesar de bastante representativos nos mercados de crédito imobiliário locais, não são os responsáveis pela ausência de condutas não competitivas observadas neste país com setor bancário altamente concentrado. Vale destacar que o incentivo à competição também foi o principal argumento para a criação desses bancos na Suíça (Novaes, 2007 como citado em Pinheiro \& Oliveira, 2007), e que acaba sendo descartado para a manutenção de sua existência.

No mercado brasileiro, também existem evidências de que os bancos públicos não têm contribuído para o aumento da competição neste espaço. Coelho, Mello e Resende (2013) utilizaram uma abordagem bastante distinta do artigo de Bichsel (2006). Os autores seguiram metodologia similar à utilizada por Bresnahan e Reiss (1991), estudando como a entrada de um banco público em um mercado local afeta a competição, em comparação com a entrada de um banco privado. Como mercados locais foram considerados cidades menores, que não fazem parte de regiões metropolitanas, resultando em uma base de quase cinco mil cidades e com uma população adulta de aproximadamente 60 milhões. Nessa amostra, foi observado que a entrada de um banco privado contribuiu mais para a competição que a entrada de um banco público, o que está de acordo com resultados anteriores. Contudo, ainda não se tem uma resposta de por que bancos privados seriam mais pró-competitivos. Os achados deste estudo indicam que a menor eficiência operacional dos bancos públicos pode acabar mitigando o seu possível objetivo de aumento de competição.

\section{Contexto do setor bancário brasileiro}

O setor bancário brasileiro sofreu forte reestruturação nos anos 90, a partir de diversas mudanças macroeconômicas incluindo restrições a operações de curto prazo no governo Collor e a subsequente implantação do Plano Real, que obteve sucesso ao reduzir as taxas de inflação em curto espaço de tempo, mas, concomitantemente, alterou a forma de geração de receitas dos bancos (Arienti, 2008; Paula \& Marques, 2004). Até então, as altas taxas de inflação garantiam aos bancos receitas de intermediação financeira que surgiam devido aos depósitos à vista e às aplicações de curto prazo (overnight) não sofrerem correção monetária integral (Vasconcelos et al., 2004). No novo cenário, os bancos viram-se obrigados a buscar fontes alternativas de receitas. A partir disto, iniciou-se expansão na oferta de crédito, que teve crescimento de 80,9\% no crédito bancário entre junho de 1994 e março de 1995 (Kretzer, 1996). Contudo, sistemas para mensuração e administração de riscos de créditos ainda não haviam sido criados, e os modelos operacionais dos bancos ainda não haviam sido ajustados, o que resultou em forte elevação dos índices de inadimplência a partir de 1995, e no surgimento de problemas financeiros em grandes 
instituições bancárias. Para controle dessa situação, foi necessária a intervenção do Banco Central (Braga, 1998) e, dentre as medidas adotadas, uma das mais debatidas foi o Programa de Estímulo à Reestruturação e ao Fortalecimento do Sistema Financeiro (PROER), lançado em novembro de 1995 (Barbosa, 2008).

O final da década de 90 foi caracterizado por uma série de fusões, aquisições e, principalmente, pela entrada de algumas instituições estrangeiras (Braga, 1998). A internacionalização do sistema bancário foi estimulada por parte do governo, segundo o discurso de que tornaria o país menos vulnerável às crises internacionais (Moura, 1998). Adiciona-se a isso a necessidade dos bancos de se adequarem aos padrões do acordo de Basileia iniciando com a primeira regulamentação do Banco Central do Brasil (BACEN) em 1988, seguida por nova revisão em 2004 (Paula \& Marques, 2006).

Nos períodos posteriores, a relação crédito/PIB apresentou queda expressiva e, somente a partir de 2003, houve retomada no crédito, que vem se mostrando consistente ao longo dos últimos anos (Oliveira, 2006). No período final dos anos 2000, além da retomada no crescimento do crédito, também pode ser observada melhora na qualidade das carteiras, manutenção da inadimplência de novas concessões, redução das taxas de juros e de spreads, ampliação dos prazos de amortização e segmentação no atendimento aos clientes (Camargo, 2009).

Apesar dos indicadores positivos, o cenário do crédito foi revertido no segundo semestre de 2008, em função da crise financeira mundial originada no mercado de crédito imobiliário norte-americano. Os bancos brasileiros, prevendo aumento na inadimplência e tendo liquidez comprometida pelos cortes mundiais de crédito, reduziram a oferta para concessão de novos contratos em busca de proteção contra possíveis perdas futuras (Freitas, 2009). Para evitar que a escassez de crédito causasse redução na atividade econômica, que já estava ameaçada pela crise mundial, o governo utilizou os bancos públicos como instrumento de atuação (Araújo \& Gentil, 2011). A proposta era que fosse aplicada estratégia anticíclica de ampliação da oferta de crédito, ao contrário do que vinha sendo feito pelo mercado em geral (Lula pede, mas bancos, 2008). O Governo Federal, desde a eleição do presidente Luiz Inácio Lula da Silva, em 2003, procurou fortalecer os bancos públicos, que se tornaram agentes importantes na execução da política de governo deste presidente.

A influência do governo nos bancos públicos para conter o spread bancário e a redução de oferta de crédito era bastante divulgada publicamente, tanto pela mídia (Faria, 2009; Sciarretta, 2008) quanto pelos discursos do presidente Lula (Secretaria de Imprensa, 2009, 2010).

Como consequência, os bancos públicos apresentaram, nesse período, forte crescimento na carteira de crédito, tomando espaço dos bancos privados (Cruz, 2008; Cucolo, 2009a). Em paralelo, outras medidas foram adotadas pelo Banco Central para incentivar uma política anticíclica, como liberação de depósitos compulsórios e intervenções no mercado de câmbio (Cucolo, 2008). Já nos primeiros meses de 2009 o mercado reagiu, e as concessões de crédito e taxas de juros voltaram aos mesmos patamares do período pré-crise (Cucolo, 2009b, 2009c). No entanto, diversos pontos negativos são levantados contra a existência dos bancos públicos. Conforme observado por Silva e Jorge (2002), os bancos públicos brasileiros apresentam menor eficiência, pois têm altos custos administrativos. Isto é uma decorrência de grande número de funcionários e agências, sendo que a remuneração de pessoal acaba tendo um peso excessivo e unidades deficitárias são mantidas por motivos políticos ou para atender populações mais afastadas dos centros urbanos. Assim, conforme discussão, embora seja possível que a menor eficiência dos bancos públicos reduza o seu efeito pró-competitivo, trata-se, em última instância, de uma questão empírica a ser examinada à luz da experiência brasileira recente. Nesse sentido, a seguir são apresentadas hipóteses sobre padrões de competição de bancos públicos e privados, a serem testadas com dados no contexto brasileiro.

\section{Hipóteses}

Enquanto os resultados acadêmicos apontam em direções opostas, governos continuam defendendo a existência dos bancos públicos, sendo o incentivo à competição um dos principais 
argumentos. Diversas críticas são geradas por isso, e análises indicam outros interesses, como o uso com finalidades política e/ou de favorecimentos (Sapienza, 2002).

Para identificar se bancos públicos incentivam a competição bancária, é necessário primeiramente confirmar se estes possuem comportamento mais competitivo que os bancos privados. A lógica é que, como discutido anteriormente, os bancos públicos possuam objetivo além de lucro. Assim, em tese, aceitariam atuar em mercados ou realizar estratégias de preços gerando menores margens. Ou seja:

H1: Os bancos públicos apresentam comportamento mais próximo à competição perfeita que os bancos privados.

É esperado, também, que os bancos públicos sejam mais sujeitos a intervenções do governo para reduzir juros, conforme ilustrado pelo próprio caso brasileiro descrito na seção anterior. Com isso, espera-se que, além de apresentar comportamento mais competitivo, os bancos públicos possam servir de ferramenta do governo para intervenção no mercado financeiro, respondendo prontamente às ações desejadas. Esse tipo de intervenção deve aumentar em momentos de crise econômica, quando os bancos públicos podem ser usados para executar políticas anticíclicas. Em outras palavras:

H2: Os bancos públicos apresentam comportamento mais próximo à competição perfeita após períodos de crise quando comparados aos seus comportamentos anteriores.

Por fim, pode-se esperar que uma mudança no comportamento dos bancos públicos seja acompanhada por mudanças de comportamento dos bancos privados. Caso essas mudanças ocorressem, poderiam ser motivadas tanto pela pressão direta do governo, quanto por uma reação dos bancos privados à mudança de comportamento de seus concorrentes públicos. Independentemente da origem dessa motivação, esse seria o desejo principal dos governantes: serem capazes de influenciar todo o mercado bancário, incluindo o comportamento de bancos públicos e privados, mesmo que, nos bancos privados, essa influência não seja tão direta. Assim, é levantada uma terceira hipótese, relativa à resposta dos bancos privados nesse período de crise, com pressões políticas do governo como tentativa de interferência no sistema financeiro:

H3: Os bancos privados apresentam comportamento mais próximo à competição perfeita após períodos de crise quando comparados ao seu comportamento em períodos anteriores.

A seguir, descreve-se a metodologia para testar essas hipóteses.

\section{Metodologia}

\section{Índice de Lerner}

Para a análise da competição bancária no Brasil ao longo dos últimos anos, será adotada a metodologia desenvolvida por Bresnahan (1982), seguindo aplicação realizada originalmente por Angelini e Cetorelli (2003), em trabalho que utilizou dados em painel para medir o nível de competição bancária no mercado italiano. $\mathrm{O}$ mesmo modelo também foi aplicado com pequenas alterações por Uchida e Tsutsui (2005) no mercado japonês e por Kubo (2006) no mercado bancário tailandês.

Nesse modelo, assume-se que os bancos definem seus preços e quantidades de forma a maximizar seus lucros. Assim, considerando que a indústria produz uma quantidade $\mathrm{Q}$ em um preço $\mathrm{p}$, e que cada firma da indústria produz uma quantidade $\mathrm{q}_{\mathrm{j}}$ e tem uma função de custo $\mathrm{C}_{\mathrm{j}}=\mathrm{C}\left(\mathrm{q}_{\mathrm{j}}, \mathrm{w}_{\mathrm{j}}\right)$, em que $\mathrm{w}_{\mathrm{j}}$ é o vetor de preços dos insumos da firma $\mathrm{j}$, os bancos maximizam a seguinte equação, em que $\mathrm{z}$ representa o vetor de variáveis exógenas que afeta a demanda:

$$
\underset{\mathrm{q}_{\mathrm{j}}}{\operatorname{Max}} \prod_{\mathrm{j}}=\mathrm{p}(\mathrm{Q}, \mathrm{z})-\mathrm{C}\left(\mathrm{q}_{\mathrm{j}}, \mathrm{w}_{\mathrm{j}}\right),
$$


Dessa forma, para maximizar (1), é necessário derivar em relação a $\mathrm{q}_{\mathrm{j}} \mathrm{e}$ igualar a zero, obtendose a equação que determina os preços e, como no caso de competição perfeita, o preço se iguala ao custo marginal $\left(\mathrm{C}^{\prime}\right)$. $\mathrm{O}$ segundo termo dessa equação pode ser interpretado como a diferença entre o preço praticado e o preço que seria praticado se o mercado estivesse em competição perfeita.

$$
p_{j}=C^{\prime}\left(q_{j}, w_{j}\right)-\frac{\Theta_{j}}{\tilde{\varepsilon}}
$$

Analisando os termos $\Theta_{\mathrm{j}}$ e $\tilde{\varepsilon}$ como fatores de elasticidade, podemos interpretá-los como a elasticidade da produção total da indústria pela produção da empresa j, e a semielasticidade da demanda do mercado pelo preço. Ou seja, $\Theta_{\mathrm{j}}$ indica o volume de aumento da produção total da indústria para cada unidade a mais produzida por uma determinada empresa, e $\tilde{\varepsilon}$ indica a variação percentual na demanda do mercado para cada unidade acrescida no preço.

Para identificar separadamente os valores de $\Theta_{\mathrm{j}}$ e $\tilde{\varepsilon}$, seria necessária a estimação simultânea da equação de oferta e demanda. Contudo, como o objetivo desta análise é de avaliar o poder de mercado exercido de forma geral por bancos públicos e privados, torna-se suficiente estimar a relação $\lambda \equiv-\Theta_{\mathrm{j}} /$ $\tilde{\varepsilon}$. Isso ocorre porque o poder de mercado nada mais é do que a capacidade de uma empresa para precificar seus produtos e serviços acima de seu custo marginal. Dessa forma, não é necessário realizar a estimativa das equações de oferta e demanda, pois se pode estimar a equação de oferta em (2) conjuntamente com a equação de custos. Para aplicação dessa metodologia, a equação de oferta toma a seguinte forma:

$$
p_{j}=C^{\prime}\left(q_{j}, w_{j}\right)+\lambda
$$

Uma visão alternativa dessa medida de nível de competição pode ser obtida dividindo $\lambda$ pelo preço; esse valor é conhecido como índice de Lerner, e deve estar limitado entre zero e um. Trata-se de uma medição muito utilizada em estudos de organização industrial e representa uma estimativa relativamente simples sobre a intensidade de competição adotada pelas firmas.

O índice de Lerner é de fácil interpretação, pois, ao assumir o valor zero, indica que há competição perfeita, e, ao assumir o valor um, indica preço de mercado de monopólio, e valores intermediários apontam em qual dos dois extremos o mercado se aproxima mais (Feinberg, 1980). Uma observação importante é que a estimativa do índice de Lerner, por meio de $\lambda$, é uma manipulação simples da fórmula mais conhecida do índice:

$$
L=\frac{p-C^{\prime}}{p}=\frac{\lambda}{p}
$$

A confirmação das hipóteses levantadas e as conclusões deste trabalho serão baseadas na interpretação do índice de Lerner. Cabe ressaltar que, embora os bancos públicos possam não trabalhar com a função objetivo de maximização de lucro, também não é esperado que trabalhem em níveis com retorno negativo (preço menor que custo marginal) (Seabra, Giglio, Fernandes, \& Meurer, 2009), assim teriam índice de Lerner menor que os bancos privados, mas não devem apresentar valores negativos.

Desta forma, para estimar adequadamente o índice de Lerner ao longo do tempo, é necessário estimar as curvas para a receita e o custo marginais dos bancos públicos e privados ao longo do tempo. A primeira etapa para a realização da análise consiste em definir as variáveis que afetam a receita e o custo dos bancos, e a segunda etapa consiste na escolha de uma metodologia econométrica adequada para a estimação simultânea dessas curvas.

\section{Modelo econométrico}

Seguindo modelo similar ao aplicado por Angelini e Cetorelli (2003), a função para os custos será especificada como segue a equação (5), em que $w_{1 j}$ representa as despesas de captação, $w_{2 j}$ representa as despesas de pessoal, $w_{3 j}$ representa as despesas de administração e outras operações de cada firma $j$, 
e a variável NPL controlará o risco de inadimplência incorrido por cada banco. Os demais coeficientes são os parâmetros da equação que serão estimados via mínimos quadrados em três estágios.

$$
\ln \left(C_{j}\right)=c_{0}+s_{0} \ln q_{j}+\frac{s_{1}}{2}\left(\ln q_{j}\right)^{2}+\sum_{i=1}^{3} c_{i} \ln w_{i j}+\ln q_{j} \sum_{i=1}^{3} s_{i+1} \ln w_{i j}+\rho \ln \left(N P L_{j}\right),
$$

A especificação da equação de custos em (5) possibilita a estimativa de uma curva de custo médio em forma de $\mathrm{U}$, que é sensível aos fatores que podem gerar economias de escala e características distintas apresentadas pelas várias firmas incluídas no modelo (Benston, Hanweck, \& Humphrey, 1982).

Para a equação de receitas, utilizou-se a seguinte especificação, também de acordo com Angelini e Cetorelli (2003), em que anog representa cada uma das g variáveis dummies indicadoras dos anos avaliados, e pub é uma variável dummy indicadora de banco público. Os demais coeficientes são os parâmetros da equação que serão estimados via mínimos quadrados em três estágios. Ainda, foram impostas as mesmas restrições entre as equações com o objetivo de aumentar a precisão das estimativas, propostas por Angelini e Cetorelli (2003).

$$
R_{j}=C_{j}\left(s_{0}+s_{1} \ln q_{j}+\sum_{i=1}^{3} s_{i+1} \ln w_{i j}\right)+\sum_{g} \lambda_{g} . \text { ano }_{g} \cdot q_{j}+\sum_{g} \lambda_{g} . \text { ano } g \cdot p u b . q_{j},
$$

As estimativas dessas equações precisam ser realizadas simultaneamente para estimação consistente dos valores de $\lambda$, que serão base para cálculo do índice de Lerner. Mediante essa estimação simultânea, será controlado o efeito de bancos com custos maiores apresentarem preços mais altos, o que poderia enviesar a análise dado que serão consideradas instituições com estruturas de custos muito distintas, a começar pela própria separação entre bancos públicos e privados (Bartel \& Harrison, 2005).

No modelo, foram usadas como variáveis de controle dummies para cada ano de período analisado e uma dummy indicadora de banco público. Os bancos já estão classificados como públicos ou privados na base de dados do Banco Central. Vale notar que as variáveis dummies de ano já controlam por efeitos temporais, como, por exemplo, mudanças econômicas no país que afetaram os bancos no período, incluindo alterações na taxa básica de juros (SELIC), além de efeitos de inadimplência sistêmica variando ao longo do tempo. Ainda consideramos que essas mudanças podem ter impacto diferenciado nas instituições privadas e públicas e, dessa forma, incluímos interações das dummies de anos com a variável dummy indicadora de banco público.

Diferentemente do realizado por Angelini e Cetorelli (2003), as regressões não serão realizadas separadamente para os diversos instantes de tempo; será, alternativamente, realizada uma regressão única, utilizando metodologia de dados em painel. Essa metodologia foi aplicada por Kubo (2006), e permite avaliar a evolução no comportamento competitivo ao longo do tempo sem novas regressões da equação de custo a cada período de tempo. Dessa maneira, será estimado um coeficiente para cada ano analisado (por meio das variáveis dummies de ano), e um coeficiente que mede a diferença entre o valor para bancos públicos e privados (interações entre as variáveis dummies de ano e a variável dummy indicadora de banco público).

A metodologia de regressão por mínimos quadrados em três estágios (3SLS), por sua vez, foi adotada para estimação do modelo devido à endogeneidade existente entre as variáveis de custo e de quantidade $\left(C_{j}\right.$ e $\left.q_{j}\right)$, sendo necessária a utilização de variáveis instrumentais. Da mesma maneira que nos trabalhos de Angelini e Cetorelli (2003), Uchida e Tsutsui (2005) e Kubo (2006), foram utilizados como instrumentos variáveis defasadas. Por causa deste, o coeficiente referente ao primeiro período de dados coletados (primeiro trimestre de 2000) não será estimado nas regressões. Apesar da perda desse período, isso não deve prejudicar as conclusões pelo longo histórico de dados coletados.

A metodologia 3SLS, desenvolvida por Zellner e Theil (1962), representa uma evolução da metodologia de regressão em dois estágios (2SLS), pois considera a correlação dos distúrbios entre as equações. Ela pode ser interpretada como uma combinação de regressão multivariada (SUR ou seemingly unrelated regression) e regressão usando mínimos quadrados em dois estágios. Basicamente, além de utilizar o primeiro estágio para estimar a matriz de momentos dos erros e o segundo estágio para estimar os coeficientes, como no procedimento 2SLS, 3SLS permite que as 
equações do sistema sejam estimadas de forma conjunta, levando em conta as covariâncias dos erros entre as equações dos 2 estágios.

\section{Dados e seleção das variáveis}

Os dados utilizados na análise foram coletados diretamente do site do Banco Central do Brasil (n.d.), no relatório Informações contábeis - 50 maiores bancos, que fornece informações do sistema Sisbacen e que possui informações trimestrais de balanço de todos os bancos com atuação no Brasil no período. Foram separadas as componentes que geram o resultado operacional, com exceção do resultado de coligadas, sendo que as componentes positivas foram consideradas como receitas e as negativas, como custos. O histórico da análise abrangerá do primeiro trimestre de 2000 ao segundo trimestre de 2011, totalizando 46 observações no tempo. Ao longo deste período, possui o número máximo de 184 instituições, e finaliza o último período com 139. Deste total, 24 bancos são públicos, sendo 5 estatais federais e 19 estatais estaduais. A listagem de todos os bancos utilizados está nas Tabelas do Anexo (A1 e A2). Considerando a totalidade das observações no tempo e das instituições, são 6.602 registros na base de dados.

A seleção das variáveis para estimação das curvas de custo e receita foi baseada em Angelini e Cetorelli (2003), Uchida e Tsutsui (2005) e Kubo (2006), e sua breve descrição está na Tabela 1. Vale destaque para a variável NPL, adicionada originalmente no trabalho de Kubo (2006), que controla o crescimento abrupto da inadimplência, dado que o período selecionado para análise inclui evento de crise do mercado de crédito. O controle de inadimplência é importante, pois pode variar entre as firmas, embora possam existir fatores sistêmicos afetando todas as firmas no mesmo ano.

Tabela 1

\section{Descrição das Variáveis Utilizadas}

\begin{tabular}{|c|c|c|}
\hline Código & Variável & Descrição detalhada \\
\hline $\mathrm{R}$ & Receitas totais & $\begin{array}{l}\text { Receitas de crédito, compulsório, títulos mobiliários, derivativos, } \\
\text { câmbio, serviços e outras operações }\end{array}$ \\
\hline $\mathrm{C}$ & Custos totais & $\begin{array}{l}\text { Despesas de empréstimos, arrendamento mercantil, captação, } \\
\text { provisão para crédito em liquidação, câmbio, pessoal, } \\
\text { administrativas, tributárias, outras operações }\end{array}$ \\
\hline$\omega_{1}$ & Taxa de captação & Despesa de captação/Depósitos totais \\
\hline$\omega_{2}$ & Custo por funcionário & Despesas de pessoal/Número de funcionários \\
\hline$\omega_{3}$ & Outras despesas operacionais & Despesas administrativas e de outras operações/Ativos totais \\
\hline NPL & Nonperforming loan & Despesas de provisão para crédito em liquidação/Ativos totais \\
\hline q & Ativos totais & \\
\hline
\end{tabular}

Existe controvérsia na literatura sobre a indústria bancária, se depósitos deveriam ser tratados como insumo ou como produto final. Está sendo aplicada a interpretação dos depósitos como insumo, e o produto final são as operações de crédito, conforme definição utilizada na maioria dos estudos empíricos sobre o mercado bancário (Kubo, 2006).

\section{Resultados}

No período analisado, houve grande aumento no volume de ativos nos bancos brasileiros (433\%), sendo que esse aumento foi maior nos bancos privados que nos bancos públicos (485\% contra 375\%). Contudo, de junho de 2008 a junho de 2011, o crescimento de ativos dos bancos privados é quase a 
metade do crescimento dos públicos (52\% contra 96\%), e isso ocorre devido ao período de setembro de 2008 a dezembro de 2009, quando os bancos privados praticamente não apresentaram crescimento de ativos (somente 3\% contra 38\% dos públicos). Tal observação é coerente ao desejo do governo de incentivar o crescimento dos bancos públicos em um período em que os privados reduziam suas ofertas de crédito.

Observa-se também que os bancos públicos têm consistentemente preços inferiores aos bancos privados, o que poderia indicar que tais bancos tenham comportamento mais competitivo. Contudo, tais preços poderiam ser totalmente explicados por custos menores, o que não caracterizaria um comportamento mais competitivo. Para esclarecer essa questão, é necessária a análise do modelo econométrico.

A estimação do modelo utilizando mínimos quadrados em três estágios (3SLS) foi realizada com o uso do software SAS, e os resultados obtidos para as equações de receitas e de custos estão na Tabela 2. Devido à altíssima correlação $(99,9 \%)$ entre as variáveis de custo e da interação entre custo e logaritmo neperiano dos ativos totais (C e C.lnq), o modelo apresenta forte de multicolinearidade e será estimado utilizando o custo (modelo 1 na Tabela 2) ou utilizando a interação entre custo e ln dos ativos totais (modelo 2), separadamente. É importante salientar que os resultados desses modelos foram bastante similares, indicando robustez da regressão.

Tabela 2

Resultados do Modelo de Regressão estimado por Mínimos Quadrados em Três Estágios

\begin{tabular}{|c|c|c|c|c|c|}
\hline \multirow[b]{2}{*}{ Equação de Custos } & \multirow{2}{*}{$\begin{array}{c}\text { Variável } \\
\text { Constante }\end{array}$} & \multicolumn{2}{|c|}{ Modelo 1} & \multicolumn{2}{|c|}{ Modelo 2} \\
\hline & & $7,7320 * * *$ & $(0,1760)$ & $5,5659 * * *$ & $(0,1838)$ \\
\hline & $\ln \_q$ & $0,1886^{* * *}$ & $(0,0088)$ & $0,3766^{* * *}$ & $(0,0073)$ \\
\hline & $\ln \_\omega_{1}$ & $0,3436 * * *$ & $(0,0389)$ & 0,0472 & $(0,0405)$ \\
\hline & $\ln \_\omega_{2}$ & $-0,1427 * * *$ & $(0,0452)$ & $0,2739 * * *$ & $(0,0470)$ \\
\hline & $\ln \_\omega_{3}$ & $1,3531 * * *$ & $(0,0477)$ & $1,4641 * * *$ & $(0,0472)$ \\
\hline & ln_npl & $0,0664 * * *$ & $(0,0040)$ & $0,0689 * * *$ & $(0,0039)$ \\
\hline & $\ln \_q^{2} / 2$ & $0,0112 * * *$ & $(0,0006)$ & $0,0186^{* * *}$ & $(0,0006)$ \\
\hline & $\ln \_\mathrm{q} \cdot \ln \_\omega_{1}$ & $-0,0435 * * *$ & $(0,0022)$ & $-0,0081 * * *$ & $(0,0026)$ \\
\hline & $\ln \_\mathrm{q} \cdot \ln \_\omega_{2}$ & $0,0179 * * *$ & $(0,0023)$ & $-0,0236^{* * *}$ & $(0,0026)$ \\
\hline & $\ln \_\mathrm{q} \cdot \ln \_\omega_{3}$ & $-0,0963 * * *$ & $(0,0022)$ & $-0,0850 * * *$ & $(0,0022)$ \\
\hline & $\ln \_\omega_{1}^{2}$ & $-0,0005$ & $(0,0013)$ & $-0,0030^{* *}$ & $(0,0014)$ \\
\hline & $\ln \_\omega_{2}^{2}$ & 0,0015 & $(0,0013)$ & $-0,0006$ & $(0,0013)$ \\
\hline & $\ln \omega_{3}{ }^{2}$ & 0,0014 & $(0,0038)$ & $0,0097 * *$ & $(0,0038)$ \\
\hline & $\ln \_\omega_{1} \cdot \ln \_\omega_{2}$ & $-0,0018 * * *$ & $(0,0061)$ & $-0,0161 * * *$ & $(0,0061)$ \\
\hline & $\ln \_\omega_{1} . \ln \_\omega_{3}$ & $-0,0730 * * *$ & $(0,0052)$ & $-0,0453 * * *$ & $(0,0053)$ \\
\hline & $\ln \_\omega_{2} \cdot \ln \_\omega_{3}$ & $0,0306^{* * *}$ & $(0,0064)$ & $-0,0040$ & $(0,0064)$ \\
\hline \multirow[t]{4}{*}{ Equação de Receitas } & $\mathrm{c}$ & $0,1886^{* * *}$ & $(0,0088)$ & & \\
\hline & c. ln_q & & & $-0,0453 * * *$ & $(0,0053)$ \\
\hline & c. $\ln \_\omega_{1}$ & $-0,0435 * * *$ & $(0,0022)$ & $-0,0040 * * *$ & $(0,0064)$ \\
\hline & c.. $\ln \omega_{2}$ & $0,0179 * * *$ & $(0,0023)$ & $-0,0453^{* * *}$ & $(0,0053)$ \\
\hline
\end{tabular}




\begin{tabular}{|c|c|c|c|c|}
\hline \multirow{3}{*}{$\begin{array}{l}\text { Variável } \\
\text { c.ln_ } \omega_{3}\end{array}$} & \multirow{2}{*}{\multicolumn{2}{|c|}{ Modelo 1}} & \multirow{2}{*}{\multicolumn{2}{|c|}{ Modelo 2}} \\
\hline & & & & \\
\hline & $-0,0963 * * *$ & $(0,0022)$ & $-0,0040 * * *$ & $(0,0064)$ \\
\hline$q \cdot d 2000$ & $0,0147 * * *$ & $(0,0018)$ & $0,0207 * * *$ & $(0,0017)$ \\
\hline$q \cdot d 2001$ & $0,0169 * * *$ & $(0,0011)$ & $0,0228 * * *$ & $(0,0010)$ \\
\hline $\mathrm{q} \cdot \mathrm{d} 2002$ & $0,0185^{* * *}$ & $(0,0010)$ & $0,0243 * * *$ & $(0,0008)$ \\
\hline$q \cdot d 2003$ & $0,0180 * * *$ & $(0,0008)$ & $0,0234 * * *$ & $(0,0007)$ \\
\hline $\mathrm{q} \cdot \mathrm{d} 2004$ & $0,0169 * * *$ & $(0,0008)$ & $0,0226 * * *$ & $(0,0007)$ \\
\hline$q \cdot d 2005$ & $0,0198 * * *$ & $(0,0007)$ & $0,0254 * * *$ & $(0,0006)$ \\
\hline$q \cdot d 2006$ & $0,0168 * * *$ & $(0,0006)$ & $0,0225^{* * *}$ & $(0,0005)$ \\
\hline$q \cdot d 2007$ & $0,0141 * * *$ & $(0,0005)$ & $0,0192 * * *$ & $(0,0004)$ \\
\hline$q \cdot d 2008$ & $0,0083^{* * *}$ & $(0,0005)$ & $0,0110 * * *$ & $(0,0004)$ \\
\hline$q \cdot d 2009$ & $0,0121 * * *$ & $(0,0005)$ & $0,0177 * * *$ & $(0,0003)$ \\
\hline$q \cdot d 2010$ & $0,0110^{* * *}$ & $(0,0004)$ & $0,0154 * * *$ & $(0,0003)$ \\
\hline $\mathrm{q} \cdot \mathrm{d} 2011$ & $0,0113 * * *$ & $(0,0004)$ & $0,0149 * * *$ & $(0,0003)$ \\
\hline $\mathrm{q} \cdot \mathrm{pub} \cdot \mathrm{d} 2000$ & $-0,0099 * * *$ & $(0,0020)$ & $-0,0101 * * *$ & $(0,0019)$ \\
\hline q $\cdot$ pub . d2001 & $-0,0122 * * *$ & $(0,0012)$ & $-0,0115 * * *$ & $(0,0011)$ \\
\hline q.pub. d2002 & $-0,0092 * * *$ & $(0,0010)$ & $-0,0092 * * *$ & $(0,001)$ \\
\hline q.pub. d2003 & $-0,0039 * * *$ & $(0,0009)$ & $-0,0040 * * *$ & $(0,0008)$ \\
\hline q. pub. d2004 & $-0,0073 * * *$ & $(0,0008)$ & $-0,0075 * * *$ & $(0,0007)$ \\
\hline$q \cdot p u b \cdot d 2005$ & $-0,0078 * * *$ & $(0,0007)$ & $-0,0083^{* * *}$ & $(0,0007)$ \\
\hline q. pub. d2006 & $-0,0064 * * *$ & $(0,0006)$ & $-0,0069 * * *$ & $(0,0006)$ \\
\hline q $\cdot$ pub . d2007 & $-0,0057 * * *$ & $(0,0004)$ & $-0,0056^{* * *}$ & $(0,0004)$ \\
\hline $\mathrm{q} \cdot \mathrm{pub} \cdot \mathrm{d} 2008$ & 0,0000 & $(0,0003)$ & $0,0024 * * *$ & $(0,0003)$ \\
\hline q · pub. d2009 & $-0,0064 * * *$ & $(0,0003)$ & $-0,0067 * * *$ & $(0,0002)$ \\
\hline q $\cdot$ pub . d2010 & $-0,0055 * * *$ & $(0,0002)$ & $-0,0053 * * *$ & $(0,0002)$ \\
\hline $\mathrm{q} \cdot \mathrm{pub} \cdot \mathrm{d} 2011$ & $-0,0055 * * *$ & $(0,0003)$ & $-0,0048 * * *$ & $(0,0002)$ \\
\hline $\mathrm{R}^{2}$ ponderado do sistema & $98,3 \%$ & & $98,4 \%$ & \\
\hline Graus de liberdade & 9.494 & & 9.494 & \\
\hline
\end{tabular}

Nota. $* \mathrm{p}<0,10 ; * *_{\mathrm{p}}<0,05 ; * * * \mathrm{p}<0,01$. Erros padrões robustos a heterocedasticidade reportados entre parênteses.

As conclusões sobre o nível de competição ao longo do tempo são baseadas na equação de receitas, que apresentou coeficientes com significância estatística e sinais conforme o esperado: positivos para os bancos privados e negativos para bancos públicos, indicando que a receita é significativamente inferior para os bancos públicos, comparada à dos bancos privados, vide Tabela 2.

O índice de Lerner, ao longo do tempo, contido nas Figuras 1 e 2, representa graficamente os resultados da Tabela 2. Usando os resultados das regressões da Tabela 2, os índices foram calculados separadamente para bancos públicos e privados ano a ano, dividindo-se os coeficientes de bancos privados e públicos pelo preço médio de cada grupo de bancos em cada ano. Pelas Figuras 1 e 2, podese observar que os bancos públicos apresentaram índice de Lerner inferior aos bancos privados (exceto na crise de 2008), indicando comportamento mais próximo à competição perfeita e confirmando a hipótese 1. 


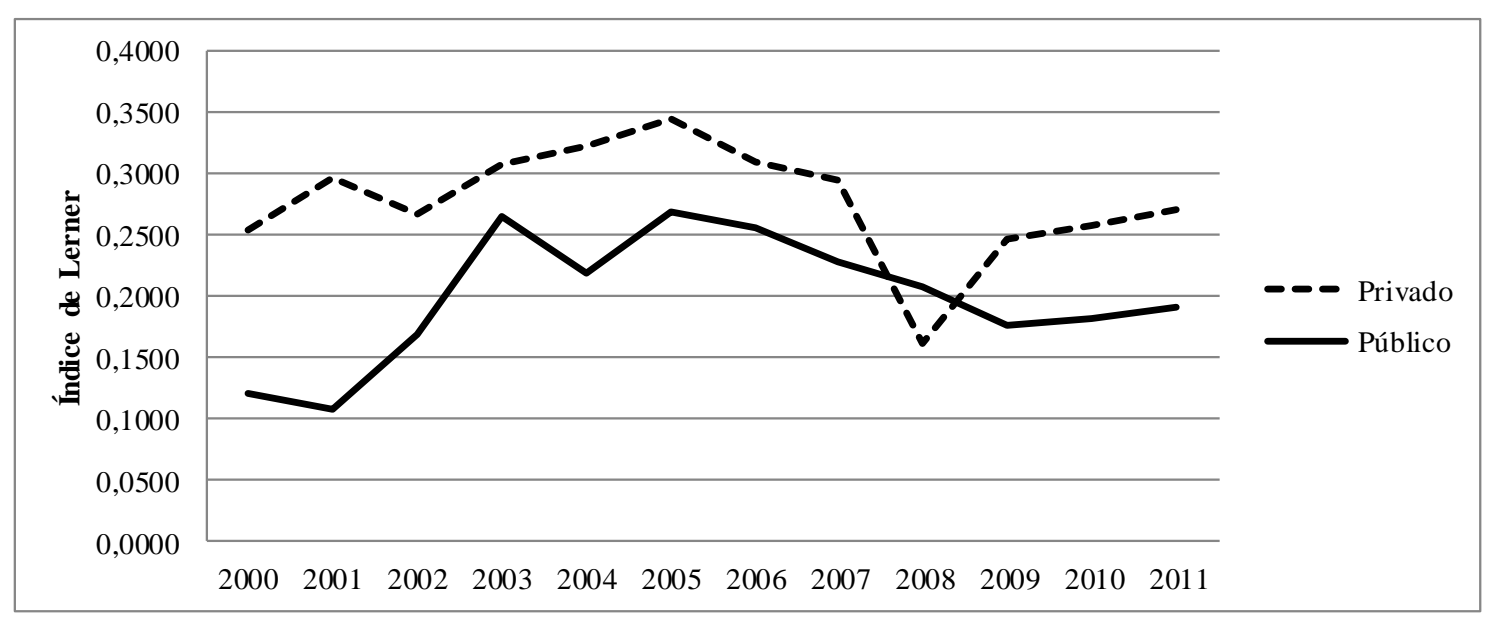

Figura 1. Índices de Lerner Estimados para Bancos Públicos e Privados (Modelo 1).

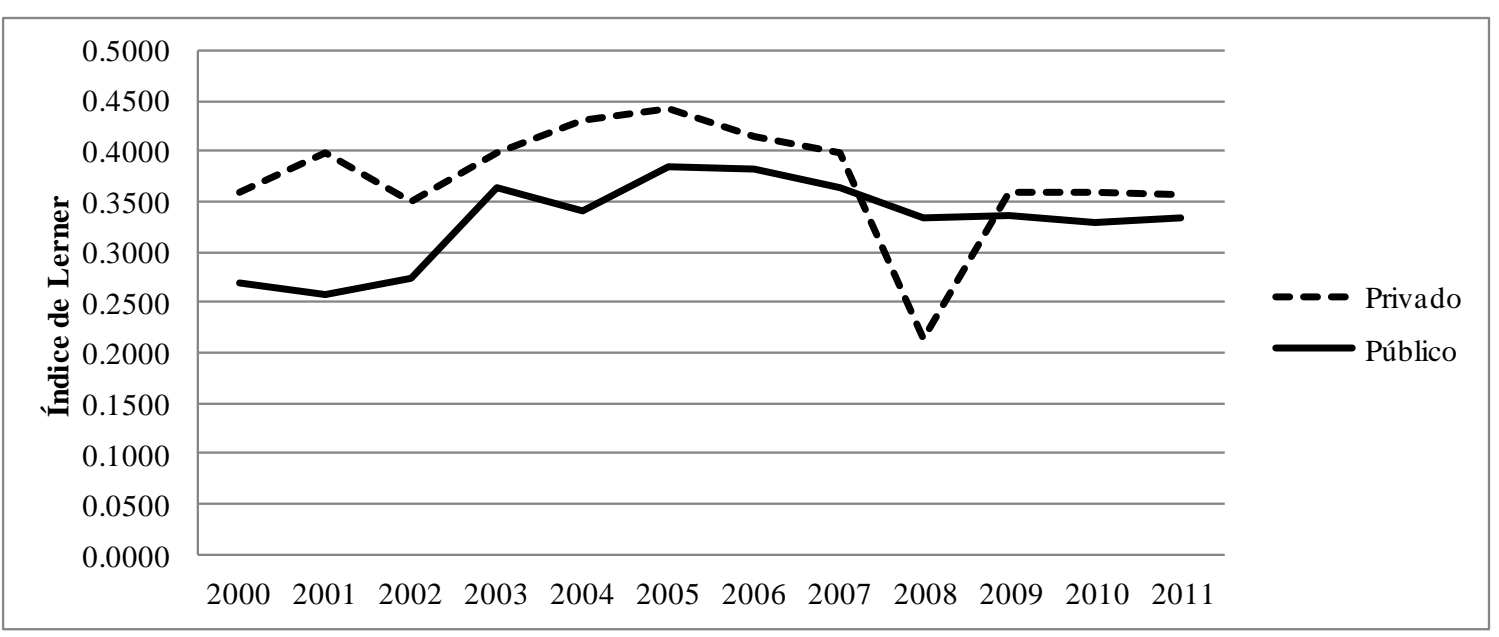

Figura 2. Índices de Lerner Estimados para Bancos Públicos e Privados (Modelo 2).

Como os coeficientes das interações entre ano e banco público, apresentados na Tabela 2, são negativos e com significância estatística para todos os anos, exceto 2008, a hipótese 1 é estatisticamente comprovada.

Já a ausência de relevância estatística para o coeficiente de 2008 no modelo 1 indica que os bancos públicos e privados apresentaram índice de Lerner estatisticamente semelhante, não diferindo em termos do grau de competição neste ano. No modelo 2, esse coeficiente de 2008 foi positivo e estatisticamente relevante, indicando que, em 2008, os bancos privados apresentaram um comportamento mais próximo à competição perfeita que os bancos públicos.

Esse comportamento pode ser explicado pelo custo bastante acima do esperado nos bancos privados. Ao separar os trimestres de 2008, confirma-se que os custos responsáveis pela queda do índice de Lerner estão concentrados no último trimestre, período de agravamento da crise. Tal aumento de custo também ocorreu para os bancos públicos, mas em grau bem menor que nos bancos privados. Neste período, houve forte crescimento tanto nos custos como nas receitas dos bancos. Porém, enquanto os bancos públicos tiveram aumento de $34 \%$ em seus custos/ativos em relação ao mesmo período do ano anterior, suas receitas/ativos cresceram $40 \%$. Já os bancos privados tiveram aumento de $82 \%$ em custos/ativos e somente $25 \%$ em receitas/ativos. Este crescimento nos custos dos bancos privados devese majoritariamente a aumentos nos custos de captação, empréstimos e outras operações. Os custos de provisão para créditos em liquidação também estão ligados à inadimplência, porém seu impacto é diluído pelos períodos seguintes. 
Pelas Figuras 1 e 2, observa-se crescimento do índice entre 2000 e 2005 tanto para bancos públicos como para bancos privados, justamente no período mais intenso de consolidação bancária. Nesse período, os bancos conseguiram melhorar seus índices de eficiência a partir da redução de custos (Camargo, 2009), apesar da notável instabilidade dos valores no período. Tal instabilidade é coerente nos dois modelos testados, mostrando que sua origem é resultado dos dados observados.

A partir de 2005, momento que o crédito/PIB começa a avançar de maneira mais consistente, pode-se notar queda nos índices de Lerner, ou seja, o aumento no volume de crédito veio acompanhado de melhora do nível de competição. Essa observação de aumento na competição também é coerente com as observações de Camargo (2009), que identificou considerável queda no spread bancário de pessoas físicas neste período. A queda de spread para pessoas físicas pode ser observada desde o ano de 2003 até os meses disponíveis o terceiro trimestre de 2011, com exceção ao período de alta entre maio e dezembro de 2008, mas já havia sido totalmente revertida em julho de 2009 (BACEN, 2011).

Uma parcela desse comportamento de queda de spread e do aumento na competição pode ser explicada pelo grande crescimento das carteiras de crédito consignado para pessoas físicas. Contudo, isso não explica totalmente a redução de preços para pessoas físicas, já que o crescimento de outras carteiras de crédito no período também é grande, e estas também apresentaram reduções em suas taxas de juros.

A partir das regressões, também pode ser observado interessante resultado que, apesar dos bancos públicos apresentarem comportamento mais próximo da competição perfeita, eles ainda exercem algum poder de mercado, pois têm índice de Lerner maior que zero. Se os bancos públicos tivessem como objetivo somente a melhoria de bem estar social via maior competição, estariam aceitando lucro econômico zero (preço igual a custo marginal), e assim teriam o resultado do índice também igual a zero. Como têm valores maiores que zero, nota-se realmente que eles convivem com objetivos mistos de rentabilidade e bem-estar social.

Apesar das eventuais ineficiências operacionais dos bancos públicos, eles conseguem manter seus preços mais baixos e ainda assim exercer algum poder de mercado. Esta observação indica que, se alcançadas melhorias nos níveis de eficiência ou se o objetivo de maior competição tivesse maior peso nos interesses dos bancos públicos, suas taxas poderiam ser ainda menores sem ter lucro econômico negativo.

Para verificação das hipóteses 2 e 3, utilizou-se um teste estatístico comparando os índices de Lerner no período anterior e no posterior à crise. Considerou-se a crise de 2008 como um evento demarcando uma mudança relevante no mercado. Assim, foi considerado como período anterior à crise os anos de 2003 a 2007, e como período posterior à crise os anos de 2009 a 2011.

A Tabela 3 apresenta a análise descritiva para os dois períodos analisados, bem como o nível descritivo do teste estatístico de Wilcoxon para comparação dos dados antes e após o ano de 2008 usando os modelos 1 e 2 da Tabela 2. Adianta-se que uma das limitações do teste é o curto período analisado, especialmente no que diz respeito aos três anos após a crise. Desta maneira, utilizou-se um teste estatístico não paramétrico (Wilcoxon), que é adequado para pequenas amostras e que não possui suposição acerca da distribuição dos dados, como normalidade, por exemplo. Com base na Tabela 3 , percebe-se que o índice de Lerner médio é inferior após 2008 tanto para bancos privados como para bancos públicos e para os dois modelos utilizados, indicando que, no período posterior à crise, os bancos aproximaram-se mais da competição perfeita. O teste estatístico confirma as hipóteses 2 e 3 com 95\% de confiança. Ressaltamos que o teste está sendo utilizado apenas como indicador dos resultados, uma vez que, apesar de ser adequado para pequenas amostras, o teste não paramétrico trabalha com a ordenação dos dados (ranks) ao invés de utilizar as médias, e, por esse mesmo motivo, os valores-p foram todos idênticos, indicando que os valores do índice de Lerner foram sempre inferiores no período posterior à crise (2009 a 2011), se comparados ao período anterior à crise (2003 a 2007). 
Tabela 3

Análise Descritiva e Teste Estatístico para Comparação do Valor Médio do Índice de Lerner nos Períodos Anterior (2003 a 2007) e Posterior (2009 a 2011) à Crise

\begin{tabular}{|c|c|c|c|c|c|c|}
\hline \multirow[b]{2}{*}{ Período } & \multicolumn{3}{|c|}{ Modelo 1 - Bancos privados } & \multicolumn{3}{|c|}{ Modelo 1 - Bancos públicos } \\
\hline & Média & Desvio padrão & valor-p & Média & Desvio padrão & valor-p \\
\hline Antes de 2008 & 0,3156 & 0,0191 & $0,036^{* *}$ & 0,2469 & 0,0232 & $0,036^{* *}$ \\
\hline \multirow[t]{2}{*}{ Após 2008} & 0,2575 & 0,0118 & & 0,1821 & 0,0076 & \\
\hline & \multicolumn{3}{|c|}{ Modelo 2 - Bancos privados } & \multicolumn{3}{|c|}{ Modelo 2 - Bancos públicos } \\
\hline Período & Média & Desvio padrão & p-valor & Média & Desvio padrão & p-valor \\
\hline Antes de 2008 & 0,4171 & 0,0195 & $0,036^{* *}$ & 0,3672 & 0,0177 & $0,036^{* *}$ \\
\hline Após 2008 & 0,3591 & 0,0018 & & 0,3337 & 0,0036 & \\
\hline
\end{tabular}

Nota. $* \mathrm{p}<0,10 ; * * \mathrm{p}<0,05 ; * * * \mathrm{p}<0,01$.

O índice de Lerner médio teve uma queda de aproximadamente 6 pontos percentuais após 2008 para os bancos privados e públicos (com base no modelo 1).

Foram realizadas análises complementares para confirmar os resultados obtidos: (a) selecionando somente bancos com receitas de crédito relevantes para seus resultados; e (b) incluindo uma variável dummy indicando bancos com estratégias focadas no segmento de baixa renda.

Apesar das receitas de crédito representarem mais da metade das receitas dos bancos brasileiros nos últimos anos, isso não é verdade para todos os bancos. Existem bancos especializados em outros tipos de operações financeiras, cuja receita de crédito apresenta uma parcela muito pequena de suas receitas totais.

Para identificação dos bancos em que o crédito é mais relevante, seguiu-se o trabalho de Gonzalez, Savóia e Gouvêa (2008), e foram selecionados bancos classificados como bancos de varejo, bancos de crédito e bancos de transição e repasses. O crédito é tratado com menor relevância para os bancos de tesouraria e de intermediação bancária. As regressões foram refeitas mantendo-se somente os bancos de crédito, de transição e repasses e de varejo, e os resultados permaneceram praticamente inalterados, validando as conclusões obtidas.

A análise que inclui variável dummy indicando estratégia ligada à baixa renda foi realizada para confirmar se os bancos públicos apresentam comportamento mais competitivo exclusivamente pela estratégia adotada. Ao gerar novo modelo com inclusão dessa variável, ela se mostra significante e positiva na equação de receitas, ou seja, indica que bancos voltados para a baixa renda geram mais receita para um mesmo risco incorrido. Contudo não são observadas diferenças nas conclusões em relação ao nível de competição. Assim, pode-se afirmar que os bancos privados possuem comportamento menos competitivo que os públicos, independentemente desses bancos terem adotado estratégias focadas para baixa renda.

\section{Conclusões}

Pela análise dos resultados obtidos, conclui-se que, no Brasil, os bancos públicos realmente apresentaram comportamento mais próximo à competição perfeita do que os bancos privados. Apesar disto, os bancos públicos também exercem poder de mercado, mesmo que menor que seus concorrentes privados. 
Pode-se observar que a crise e a influência do Estado interferiram de maneira significante no comportamento competitivo dos bancos. Tanto os bancos públicos como os bancos privados apresentaram mudança de comportamento em termos de competição após as declarações de incentivo à concessão de crédito e à redução de taxas por parte do governo federal brasileiro durante a crise de 2008. Desta forma, os bancos públicos podem ser vistos como instrumento direto de influência do governo no mercado bancário.

Vale notar que, posteriormente ao recorte temporal desse estudo, no primeiro semestre de 2012, o governo induziu os bancos públicos a cortes mais agressivos nos juros. Essa ação pode ter afetado acentuadamente a lucratividade desses bancos, levando-os provavelmente ainda mais na direção de maior competição. Assim, há a oportunidade de novos estudos englobando eventos mais recentes no setor bancário brasileiro.

Salientamos que estudos adicionais são necessários para identificar e quantificar a influência do comportamento dos bancos públicos no nível de competição dos bancos privados. Posteriores desenvolvimentos devem considerar também a causalidade dos efeitos de alterações de comportamento dos bancos; por exemplo, se bancos privados geram respostas competitivas dos bancos públicos ou viceversa. Além disso, o presente estudo faz uma distinção dicotômica entre bancos públicos e privados. Pesquisas futuras poderiam analisar diferentes tipos de bancos públicos e privados, atendendo a segmentos de mercado diversos e com estratégias de crédito heterogêneas.

Além disto, uma observação interessante é que tanto os bancos públicos como os bancos privados passaram por um período de piora no nível de competição até 2005, que foi gerado por aumento de sua eficiência de custos, para, nos anos seguintes, reduzirem o nível de competição pelo lado da mudança de preço. Dessa forma, ao analisar o bem-estar social, é fundamental o acompanhamento conjunto do nível de competição e do preço cobrado, já que as empresas podem acabar passando por um período inicial de redução de custos para posteriormente conseguirem competir em preços. Nesse caso, em se analisado somente indicadores de competição, seria observada uma piora do nível de competição seguida posteriormente por um retorno ao patamar anterior, mas o resultado deste comportamento é benéfico para a população, pois a redução de competição não foi consequência de um aumento de preços.

Por fim, a pesquisa contribui para a literatura pela aplicação no mercado brasileiro de uma técnica de estimação da competição bancária utilizando regressões em três estágios. As observações permaneceram coerentes com estudos anteriores (Angelini \& Cetorelli, 2003; Kubo, 2006; Uchida \& Tsutsui, 2005), reforçando e contribuindo no desenvolvimento dessa metodologia ainda pouco explorada no Brasil. O uso de ampla base de dados, longo período histórico e diferentes critérios de estimação garante maior robustez do método e maior confiabilidade dos resultados.

\section{Referências}

Ahroni, Y. (1986). The evolution and management of state owned enterprises. Cambridge: Ballinger Publishing.

Amsden, A. (2001). The rise of 'the rest': challenges to the west from late-industrializing economies. Oxford: Oxford University Press.

Angelini, P., \& Cetorelli, N. (2003). The effects of regulatory reform on competition in the banking industry. Journal of Money, Credit, and Banking, 35(5), 663-684. doi: 10.1353/mcb.2003.0033

Araújo, V. L., \& Gentil, D. L. (2011). Avanços, recuos, acertos e erros: uma análise da resposta da política econômica brasileira à crise financeira internacional [Texto para discussão, $\mathrm{N}^{\circ}$ 1602]. Brasília, DF: IPEA. 
Arienti, F. F. (2008). Reestruturação e consolidação do sistema bancário privado brasileiro. Ensaios FEE, 28(2), 577-600.

Banco Central do Brasil. (n.d.). 50 maiores bancos e o consolidado do Sistema Financeiro Nacional. Recuperado de http://www4.bcb.gov.br/top50/port/top50.asp

Barbosa, F. H. (2008). Banco nacional: jogo de Ponzi, PROER e FCVS. Revista de Economia Política, 28(1), 97-115. doi: 10.1590/S0101-31572008000100005

Bartel, A. P., \& Harrison, A. E. (2005). Ownership versus environment: disentangling the sources of public-sector inefficiency. The Review of Economics and Statistics, 87(1), 135-147.

Benston, G. J., Hanweck, G. A., \& Humphrey, D. B. (1982). Scale economies in banking: a restructuring and reassessment. Journal of Money, Credit and Banking, Blackwell Publishing, 14(4), 435-456.

Bichsel, R. (2006). State-owned banks as competition enhancers, or the grand illusion. Journal of Finacial Services Research, 30(2), 117-150. doi: 10.1007/s10693-006-0015-7

Braga, M. B. (1998, setembro). Os bancos brasileiros e a crise mundial. Boletim Informações Fipe, (216), 15-16.

Bresnahan, T. F. (1982). The oligopoly solution concept is identified. Economics Letters, 10(1/2), 8792. doi: 10.1016/0165-1765(82)90121-5

Bresnahan, T. F., \& Reiss, P. C. (1991). Entry and competition in concentrated markets. Journal of Political Economy, 99(5), 977-1009.

Camargo, P. O. (2009). A evolução recente do setor bancário no Brasil (Dissertação de mestrado). Faculdade de Ciências e Letras da Universidade Estadual Paulista Júlio de Mesquita Filho, UNESP, Araraquara, SP, Brasil.

Coelho, C. A., Mello, J. M. P. de, \& Rezende, L. (2013). Do public banks compete with private banks? Evidence from concentrated local markets in Brazil. Journal of Money, Credit, and Banking, 45(8), 1581-1615. doi: 10.1111/jmcb.12063

Cruz, N. H. D. (2008, novembro 29). Banco público puxa expansão do crédito e ganha espaço de privado. Folha de S. Paulo. Recuperado de http://www1.folha.uol.com.br/folha/dinheiro/ult91u473179.shtml

Cucolo, E. (2008, outubro 29). Veja a lista de medidas já anunciadas no Brasil para combater a crise. Folha Online. Recuperado de http://www1.folha.uol.com.br/folha/dinheiro/ult91u455919.shtml

Cucolo, E. (2009a, março 18). BB diz que carteira de crédito cresceu 13\% após início da crise. Folha Online. Recuperado de http://www1.folha.uol.com.br/folha/dinheiro/ult91u536740.shtml

Cucolo, E. (2009b, fevereiro 9). Concessões de crédito cresceram 1,1\% desde o início da crise, diz Meirelles. Folha Online. Recuperado de http://www1.folha.uol.com.br/folha/dinheiro/ult91u501032.shtml

Cucolo, E. (2009c, março 26). Taxa do cheque especial cai em fevereiro e volta aos níveis pré-crise. Folha Online. Recuperado de http://www1.folha.uol.com.br/folha/dinheiro/ult91u540866.shtml

Dinç, I. S. (2005). Politicians and banks: political influences on government-owned banks in emerging markets. Journal of Financial Economics, 77(2), 453-479. doi: 10.1016/j.jfineco.2004.06.011

Faria, T. (2009, janeiro 27). Problema do Brasil com a crise ainda é crédito, diz Lula. Folha Online. Recuperado de http://www1.folha.uol.com.br/folha/dinheiro/ult91u495106.shtml 
Feinberg, R. M. (1980). The Lerner index, concentration, and the measurement of market power. Southern Economic Journal, 46(4), 1180-1186.

Freitas, M. C. P. (2009). Os efeitos da crise global no Brasil: aversão ao risco e preferência pela liquidez no mercado de crédito. Estudos Avançados, 23(66), 125-145. doi: 10.1590/S010340142009000200011

Gerschenkron, A. (1962). Economic backwardness in historical perspective. Cambridge: Harvard University Press.

Gonzalez, R. B., Savoia, J. R. F., \& Gouvêa, M. A. (2008). Grupos estratégicos bancários: uma abordagem transversal multivariada para o problema da segmentação dos bancos no Brasil. Revista de Administração Mackenzie, 9(7), 11-40. doi: 10.1590/S1678-69712008000700002

Kretzer, J. (1996). Os efeitos das fusões e incorporações na estrutura do mercado bancário brasileiro: 1964-1984 (Dissertação de mestrado). Universidade Federal de Santa Catarina, Florianópolis, SC, Brasil.

Kubo, K. (2006). The degree of competition in the thai banking industry before and after the East Asian crisis. ASEAN Economic Bullelin, 23(1), 325-340.

La Porta, R., Lopez-de-Silanes, F., \& Shleifer, A. (2002). Government ownership of banks. The Journal of Finance, 57(1), 265-301. doi: 10.1111/1540-6261.00422

Levy-Yeyati, E., Micco, A., \& Panizza, U. (2004). Should the government be in the banking business? The role of state-owned and development banks [Working Paper $\mathrm{n}^{\circ}$ 517]. Inter-American Development Bank, Research Department, Washington, USA.

Lula pede, mas bancos não elevam crédito. (2008, outubro 28). Folha Online. Recuperado de http://www1.folha.uol.com.br/folha/dinheiro/ult91u461210.shtml

Matthey, A. (2010). Do public banks have a competitive advantage? European Journal of Finance, 16(1/2), 45-55.

Megginson, W. L. (2005). The financial economics of privatization. New York: Oxford University Press.

Micco, A., \& Panizza, U. (2006). Bank ownership and lending behavior. Econonmic Letters, 93(2), 248254. doi: 10.1016/j.econlet.2006.05.009

Moura, A. (1998, dezembro). Sistema financeiro nacional (Painel III). Anais do Encontro Nacional sobre Mercados Financeiros, Política Monetária e Política Cambial, Rio de Janeiro, RJ, Brasil, 4.

Musacchio, A., \& Lazzarini, S. G. (2014). Reinventing state capitalism: leviathan in business, Brazil and beyond. Cambridge: Cambridge University Press.

Oliveira, G. C. D. (2006). O comportamento recente do crédito e da estrutura patrimonial de grandes bancos no Brasil (2002-2005): uma abordagem pós-keynesiana. Anais do XI Encontro da Sociedade Brasileira de Economia Política.

Paula, L. F. de, \& Marques, M. B. L. (2004). Tendências recentes da consolidação bancária no Brasil. Análise Econômica, 24(45), 235-263.

Pinheiro, A. C., \& Oliveira, L. C., de, Filho (2007). Mercado de capitais e bancos públicos. São Paulo, Rio de Janeiro: Contra Capa Livraria/ANBID.

Sapienza, P. (2002) What do State-owned firms maximize? Evidence from the Italian banks. [Discussion Paper, $N^{\circ}$ 3.186]. London: Centre for Economic Policy Research. 
Sciarretta, T. (2008, outubro 21). Pressão do governo em bancos oficiais preocupa analistas. Folha de S.Paulo. Recuperado de http://www1.folha.uol.com.br/folha/dinheiro/ult91u458481.shtml

Shapiro, C., \& Willig, R. D. (1990). Economic rationales for the scope of privatization. In E. Suleiman \& J. Waterbury (Eds.), The political economy of public sector reform and privatization (pp. 5587). London: Westview Press.

Seabra, F., Giglio, R. F., Fernandes, R. L., \& Meurer, R. (2009). Existe comportamento diferenciado entre bancos públicos e privados em relação à política monetária? Pesquisa \& Debate, 20(1), 97111 .

Secretaria de Imprensa. (2009, fevereiro). Discurso do Presidente da República, Luiz Inácio Lula da Silva, durante solenidade de posse da diretoria do Sebrae. Brasília-DF. Recuperado de http://www.biblioteca.presidencia.gov.br/ex-presidentes/luiz-inacio-lula-da-silva/discursos/2omandato/2009/1o-semestre/04-02-2009-discurso-do-presidente-da-republica-luiz-inacio-lula-dasilva-durante-solenidade-de-posse-da-diretoria-do-sebrae/view

Secretaria de Imprensa. (2010, março). Discurso do Presidente da República, Luiz Inácio Lula da Silva, durante cerimônia de encerramento do Encontro de Administradores do Banco do Brasil no estado de São Paulo. São Paulo-SP. Recuperado de http://www.biblioteca.presidencia.gov.br/expresidentes/luiz-inacio-lula-da-silva/discursos/2o-mandato/2010/1o-semestre/02-03-2010discurso-do-presidente-da-republica-luiz-inacio-lula-da-silva-durante-cerimonia-deencerramento-do-encontro-de-administradores-do-banco-do-brasil-no-estado-de-sao-paulo/view

Silva, T. L. D., \& Jorge, P. D. M., Neto. (2002). Economia de escala e eficiência nos bancos brasileiros após o Plano Real. Estudos Econômicos,32(4), 577-619.

Uchida, H., \& Tsutsui, Y. (2005). Has competition in the Japanese banking sector improved? Journal of Banking \& Finance, 29(2), 419-439. doi: 10.1016/j.jbankfin.2004.05.013

Vasconcelos, M. R., Fucidji, J. R., Scorzafave, L. G., \& Assis, D. L. (2004). O todo e as partes: uma análise da desigualdade de crédito entre os estados brasileiros e os determinantes do crédito bancário com a aplicação de dados em painel. Economia e Sociedade, 13(1), 123-149.

Zellner, A., \& Theil, H. (1962). Three-stage least squares: simultaneous estimation of simultaneous equations. Econometrica, 30(1), 54-78. 


\section{ANEXOS}

Tabela A1

Listagem e Classificação dos Bancos Utilizados

\begin{tabular}{|c|c|c|c|c|c|c|c|}
\hline Instituições Financeiras & $\begin{array}{l}\text { Banco de } \\
\text { Crédito, } \\
\text { Varejo ou } \\
\text { Transição } \\
\text { e Repasses }\end{array}$ & $\begin{array}{l}\text { Estratégia } \\
\text { voltada } \\
\text { para baixa } \\
\text { renda }\end{array}$ & $\begin{array}{c}\text { Banco } \\
\text { Público }\end{array}$ & Instituições Financeiras & $\begin{array}{l}\text { Banco de } \\
\text { Crédito, } \\
\text { Varejo ou } \\
\text { Transição } \\
\text { e Repasses }\end{array}$ & $\begin{array}{l}\text { Estratégia } \\
\text { voltada } \\
\text { para baixa } \\
\text { renda }\end{array}$ & $\begin{array}{c}\text { Banco } \\
\text { Público }\end{array}$ \\
\hline ABC-BRASIL & $\mathrm{X}$ & & & BOAVISTA & $\mathrm{X}$ & & \\
\hline ABN AMRO & $\mathrm{X}$ & & & $\mathrm{BOC}$ & & & \\
\hline AGF & & & & BONSUCESSO & $\mathrm{X}$ & & \\
\hline AGF BRASEG & & & & BOREAL & & & \\
\hline ALFA & $\mathrm{X}$ & & & BOSTON N.A. & & & \\
\hline AMEX & $\mathrm{X}$ & & & BPN BRASIL & $\mathrm{X}$ & & \\
\hline ARAUCARIA & $\mathrm{X}$ & & & BRACCE & & & \\
\hline ARBI & & & & BRADESCO & $\mathrm{X}$ & $\mathrm{X}$ & \\
\hline AZTECA & $\mathrm{X}$ & $\mathrm{X}$ & & BRASCAN & & & \\
\hline BANCAP & $\mathrm{X}$ & & & BRB & $\mathrm{X}$ & $\mathrm{X}$ & $\mathrm{X}$ \\
\hline BANCNACION & $X$ & & & BRDE & $\mathrm{X}$ & & $X$ \\
\hline BANCO ABB & & & & BRJ & $\mathrm{X}$ & & \\
\hline BANCO AXIAL & & & & BTG PACTUAL & & & \\
\hline BANCO GMAC & $\mathrm{X}$ & & & BTMUB & & & \\
\hline BANCO RANDON S.A. & $\mathrm{X}$ & & & BVA & $\mathrm{X}$ & & \\
\hline BANCO TOPÁZIO & & & & BYM & $\mathrm{X}$ & & \\
\hline BANCOCIDADE & $\mathrm{X}$ & & & CACIQUE & $\mathrm{X}$ & $\mathrm{X}$ & \\
\hline BANCOOB & & & & CARGILL & & & \\
\hline BANDEIRANTES & $\mathrm{X}$ & & & CARREFOUR & $\mathrm{X}$ & $\mathrm{X}$ & \\
\hline BANDES & $\mathrm{X}$ & & $\mathrm{X}$ & CCF BRASIL & & & \\
\hline BANESE & $\mathrm{X}$ & & $\mathrm{X}$ & CEDULA & $\mathrm{X}$ & & \\
\hline BANESPA & $\mathrm{X}$ & $\mathrm{X}$ & $\mathrm{X}$ & CEF & $\mathrm{X}$ & & $X$ \\
\hline BANESTADO & $\mathrm{X}$ & $\mathrm{X}$ & $X$ & CHASE & & & \\
\hline BANESTES & $\mathrm{X}$ & & $\mathrm{X}$ & CITIBANK & $\mathrm{X}$ & & \\
\hline BANIF & $\mathrm{X}$ & & & CLASSICO & & & \\
\hline BANK OF AMERICA & & & & CNH CAPITAL & $\mathrm{X}$ & & \\
\hline BANKBOSTON & $\mathrm{X}$ & & & CONCÓRDIA & & & \\
\hline BANPARA & $\mathrm{X}$ & & $\mathrm{X}$ & CONFIDENCE & & & \\
\hline BANRISUL & $\mathrm{X}$ & & $\mathrm{X}$ & CR2 & $\mathrm{X}$ & & \\
\hline BANSICREDI & & & & CREDIBEL & & & \\
\hline BARCLAYS & & & & CREDIT AGRICOLE & & & \\
\hline BARCLAYS GALICIA & $\mathrm{X}$ & & & CREDIT LYONNAIS & $\mathrm{X}$ & & \\
\hline
\end{tabular}




\section{Tabela A1 (continuação)}

\begin{tabular}{|c|c|c|c|c|c|c|c|}
\hline Instituições Financeiras & $\begin{array}{l}\text { Banco de } \\
\text { Crédito, } \\
\text { Varejo ou } \\
\text { Transição } \\
\text { e Repasses }\end{array}$ & $\begin{array}{l}\text { Estratégia } \\
\text { voltada } \\
\text { para baixa } \\
\text { renda }\end{array}$ & $\begin{array}{c}\text { Banco } \\
\text { Público }\end{array}$ & Instituições Financeiras & $\begin{array}{l}\text { Banco de } \\
\text { Crédito, } \\
\text { Varejo ou } \\
\text { Transição } \\
\text { e Repasses }\end{array}$ & $\begin{array}{l}\text { Estratégia } \\
\text { voltada } \\
\text { para baixa } \\
\text { renda }\end{array}$ & $\begin{array}{c}\text { Banco } \\
\text { Público }\end{array}$ \\
\hline BASA & $\mathrm{X}$ & & $\mathrm{X}$ & CREDIT SUISSE & & & \\
\hline BASEMSA & $\mathrm{X}$ & & & CRUZEIRO DO SUL & & & \\
\hline BB & $\mathrm{X}$ & $\mathrm{X}$ & $\mathrm{X}$ & CSF & & & \\
\hline BBA-CREDITANSTALT & $\mathrm{X}$ & & & CSFB GARANTIA & & & \\
\hline BBM & & & & DAIMLERCHRYSLER & $\mathrm{X}$ & & \\
\hline BBVA BR & & & & DAYCOVAL & & & \\
\hline BCGB & & & & DBB BM & & & \\
\hline BCO CIT BRASIL & $\mathrm{X}$ & & & DESENBANCO & $\mathrm{X}$ & & $\mathrm{X}$ \\
\hline BCO JOHN DEERE & $\mathrm{X}$ & & & DEUTSCHE & & & \\
\hline BCOMURUGUAI & $\mathrm{X}$ & & & DIDIER LEVY & & & \\
\hline BDMG & $\mathrm{X}$ & & $X$ & DRESDNER & & & \\
\hline BEA & $\mathrm{X}$ & & $\mathrm{X}$ & EMBLEMA & & & \\
\hline BEC & & & $\mathrm{X}$ & EQUITY & & & \\
\hline BEG & $\mathrm{X}$ & $\mathrm{X}$ & $\mathrm{X}$ & EUROINVEST & $X$ & & \\
\hline BEM & $\mathrm{X}$ & $\mathrm{X}$ & $\mathrm{X}$ & EUROPEU & & & \\
\hline BEPI & $\mathrm{X}$ & $\mathrm{X}$ & $\mathrm{X}$ & FATOR & & & \\
\hline BES & & & & FIAT & $\mathrm{X}$ & & \\
\hline BESC & & & $\mathrm{X}$ & FIBRA & & & \\
\hline BGN & $\mathrm{X}$ & & & FICRISA AXELRUD & $\mathrm{X}$ & & \\
\hline BIC & $\mathrm{X}$ & & & FICSA & $\mathrm{X}$ & & \\
\hline BILBAO VIZCAYA & $\mathrm{X}$ & & & FIDIS & $\mathrm{X}$ & & \\
\hline $\mathrm{BM} \& \mathrm{~F}$ & & & & FINANCIAL & & & \\
\hline BMC & $\mathrm{X}$ & & & FINANSINOS & $\mathrm{X}$ & & \\
\hline BMG & $\mathrm{X}$ & $\mathrm{X}$ & & FININVEST & $\mathrm{X}$ & & \\
\hline BNB & $X$ & & $X$ & FONTE CINDAM & & & \\
\hline BNDES & $\mathrm{X}$ & & $\mathrm{X}$ & FORD & $\mathrm{X}$ & & \\
\hline BNL & $\mathrm{X}$ & & & FRANCES INTER & & & \\
\hline BNP & & & & GE CAPITAL & $X$ & & \\
\hline BNP PARIBAS & & & & GENERAL MOTORS & $\mathrm{X}$ & & \\
\hline
\end{tabular}

Nota. Fonte: elaborado pelos autores a parti de Gonzalez, R. B., Savoia, J. R. F., \& Gouvêa, M. A. (2008). Grupos estratégicos bancários: uma abordagem transversal multivariada para o problema da segmentação dos bancos no Brasil. Revista de Administração Mackenzie, 9(7), 11-40. doi: 10.1590/S1678-69712008000700002 
Tabela A2

Listagem e Classificação dos Bancos Utilizados

\begin{tabular}{|c|c|c|c|c|c|c|c|}
\hline Instituições Financeiras & $\begin{array}{c}\text { Banco de } \\
\text { Crédito, } \\
\text { Varejo ou } \\
\text { Transição } \\
\text { e Repasses }\end{array}$ & $\begin{array}{l}\text { Estratégia } \\
\text { voltada } \\
\text { para baixa } \\
\text { renda }\end{array}$ & $\begin{array}{l}\text { Banco } \\
\text { Público }\end{array}$ & Instituições Financeiras & $\begin{array}{c}\text { Banco de } \\
\text { Crédito, } \\
\text { Varejo ou } \\
\text { Transição } \\
\text { e Repasses }\end{array}$ & $\begin{array}{c}\text { Estratégia } \\
\text { voltada } \\
\text { para baixa } \\
\text { renda }\end{array}$ & $\begin{array}{l}\text { Banco } \\
\text { Público }\end{array}$ \\
\hline GERAÇÃO FUTURO & & & & OURINVEST & $\mathrm{X}$ & & \\
\hline GERADOR & $X$ & & & PACTUAL & & & \\
\hline GERDAU & $\mathrm{X}$ & & & PANAMERICANO & $\mathrm{X}$ & $\mathrm{X}$ & \\
\hline GM & $\mathrm{X}$ & & & PARAIBAN & & & $\mathrm{X}$ \\
\hline GOLDMAN SACHS & & & & PARANA & $\mathrm{X}$ & & \\
\hline GRAPHUS & & & & PATAGON & & & \\
\hline GUANABARA & $\mathrm{X}$ & & & PEBB & & & \\
\hline HEXABANCO & & & & PECUNIA & $\mathrm{X}$ & & \\
\hline HONDA & $\mathrm{x}$ & & & PERFORMANCE & & & \\
\hline HSBC & $\mathrm{x}$ & & & PETRA & & & \\
\hline IBIBANK & $\mathrm{x}$ & $\mathrm{X}$ & & PINE & $\mathrm{X}$ & & \\
\hline IBM & $\mathrm{x}$ & & & PORTO REAL & $\mathrm{X}$ & & \\
\hline ICATU & & & & PORTO SEGURO & & & \\
\hline INDUSCRED & & & & POTTENCIAL & $\mathrm{X}$ & & \\
\hline INDUSTRIAL DO BRASIL & $\mathrm{X}$ & & & PRIME & & & \\
\hline INDUSVAL & $\mathrm{x}$ & & & PRIMUS & $\mathrm{X}$ & & \\
\hline ING & & & & PROSPER & & & \\
\hline INTER AMEX & $\mathrm{X}$ & & & PSA FINANCE & $\mathrm{X}$ & & \\
\hline INTERCAP & $\mathrm{x}$ & & & RABOBANK & & & \\
\hline INTERIOR & $\mathrm{x}$ & & & REDE & & & \\
\hline INTERMEDIUM & $\mathrm{x}$ & & & RENDIMENTO & $\mathrm{X}$ & & \\
\hline INTERPART & $\mathrm{x}$ & & & RENNER & $\mathrm{x}$ & & \\
\hline INVESTCRED & $\mathrm{X}$ & & & RIBEIRAO PRETO & $\mathrm{X}$ & & \\
\hline INVESTOR & & & & RODOBENS & $\mathrm{X}$ & & \\
\hline ITAU & $\mathrm{X}$ & & & ROYAL INVEST & $\mathrm{X}$ & & \\
\hline J. MALUCELLI & $\mathrm{X}$ & $\mathrm{X}$ & & RURAL & $\mathrm{X}$ & & \\
\hline JBS BANCO & & & & SAFRA & $\mathrm{X}$ & & \\
\hline JOHN DEERE & $\mathrm{X}$ & & & SANTANDER & $\mathrm{X}$ & & \\
\hline JP MORGAN & & & & SANTANDER BANESPA & $\mathrm{X}$ & & \\
\hline JP MORGAN CHASE & & & & SANTANDER BRASIL & $\mathrm{X}$ & & \\
\hline KDB BRASIL & & & & SANTOS & $\mathrm{X}$ & & \\
\hline KEB & & & & SANTOS NEVES & $\mathrm{X}$ & & \\
\hline LA PROVINCIA & & & & SCANIA BANCO S.A. & $\mathrm{X}$ & & \\
\hline LA REPUBLICA & & & & SCHAHIN & $\mathrm{X}$ & & \\
\hline LAGE LANDEN & $\mathrm{X}$ & & & SMBC & & & \\
\hline
\end{tabular}


Tabela A2 (continuação)

\begin{tabular}{|c|c|c|c|c|c|c|c|}
\hline Instituições Financeiras & $\begin{array}{l}\text { Banco de } \\
\text { Crédito, } \\
\text { Varejo ou } \\
\text { Transição } \\
\text { e Repasses }\end{array}$ & $\begin{array}{l}\text { Estratégia } \\
\text { voltada } \\
\text { para baixa } \\
\text { renda }\end{array}$ & $\begin{array}{c}\text { Banco } \\
\text { Público }\end{array}$ & Instituições Financeiras & $\begin{array}{l}\text { Banco de } \\
\text { Crédito, } \\
\text { Varejo ou } \\
\text { Transição } \\
\text { e Repasses }\end{array}$ & $\begin{array}{l}\text { Estratégia } \\
\text { voltada } \\
\text { para baixa } \\
\text { renda }\end{array}$ & $\begin{array}{c}\text { Banco } \\
\text { Público }\end{array}$ \\
\hline LEMON & & & & SOCIETE GENERALE & & & \\
\hline LEMON BANK & & & & SOCOPA & $\mathrm{X}$ & & \\
\hline LIBERAL & & & & SOFISA & $\mathrm{X}$ & & \\
\hline LLOYDS & & & & SS & $\mathrm{X}$ & & \\
\hline LUSO BRASILEIRO & $\mathrm{X}$ & & & STANDARD BI & & & \\
\hline MALCON & $\mathrm{X}$ & & & STANDARD CHASTERED & & & \\
\hline MARKA & & & & STERLING & $\mathrm{X}$ & & \\
\hline MATONE & $\mathrm{X}$ & & & STOCK & & & \\
\hline MATRIX & $\mathrm{X}$ & & & SUDAMERIS & $\mathrm{X}$ & & \\
\hline MÁXIMA & & & & SUL AMERICA & & & \\
\hline MAXINVEST & $\mathrm{X}$ & & & SUMITBANK & & & \\
\hline MERCANTIL DO BRASIL & $\mathrm{X}$ & & & TENDENCIA & & & \\
\hline MERCANTIL FINASA & $\mathrm{X}$ & & & THECA & & & \\
\hline MERCANTIL SP & $\mathrm{X}$ & & & TOKYOMITSUBISHI & & & \\
\hline MERCEDES-BENZ & $\mathrm{X}$ & & & TOYOTA & $\mathrm{X}$ & & \\
\hline MERIDIONAL & $\mathrm{X}$ & & & TRIANGULO & $\mathrm{X}$ & & \\
\hline MERRILL LYNCH & & & & TRICURY & $\mathrm{X}$ & & \\
\hline MINAS & $\mathrm{X}$ & & & UBS PACTUAL & & & \\
\hline MISASI & & & & UBS WARBURG & & & \\
\hline MODAL & $\mathrm{X}$ & & & UNIBANCO & $\mathrm{X}$ & & \\
\hline MONEO & $\mathrm{X}$ & & & UNION & & & \\
\hline MORADA & $\mathrm{X}$ & & & UNO-E & & & \\
\hline MORGAN STANLEY & & & & VOLKSWAGEN & $\mathrm{X}$ & & \\
\hline MULTI & & & & VOLVO & $\mathrm{X}$ & & \\
\hline NACOES & $\mathrm{X}$ & & & VOTORANTIM & & & \\
\hline NATIXIS & & & & VR & $\mathrm{X}$ & & \\
\hline NOSSA CAIXA & $\mathrm{X}$ & $\mathrm{X}$ & $\mathrm{X}$ & WACHOVIA & & & \\
\hline OK & $\mathrm{X}$ & & & WESTLB & & & \\
\hline OPPORTUNITY & & & & ZOGBI & $X$ & $X$ & \\
\hline
\end{tabular}

Nota. Fonte: elaborado pelos autores a parti de Gonzalez, R. B., Savoia, J. R. F., \& Gouvêa, M. A. (2008). Grupos estratégicos bancários: uma abordagem transversal multivariada para o problema da segmentação dos bancos no Brasil. Revista de Administração Mackenzie, 9(7), 11-40. doi: 10.1590/S1678-69712008000700002 